\title{
Complications of diabetes: renal disease and promotion of self-management
}

\author{
A Melville, R Richardson, D Lister-Sharp, A McIntosh
}

This paper is an edited version of Effective Health Care volume 6 number $1,{ }^{1}$ which summarises information originally derived from systematic reviews undertaken to inform national clinical practice guidelines, ${ }^{23}$ supplemented and re-analysed by the NHS Centre for Reviews and Dissemination.

\section{Renal complications of type 2 diabetes}

Raised blood glucose levels and related microvascular disease are associated with progressive damage to the kidneys. This damage becomes detectable when protein (primarily albumin) is excreted in the urine in higher concentrations than normal. As the severity of the damage increases, the quantity of protein in the urine also increases. When the level of albumin in the urine is fairly low, the condition is known as microalbuminuria or incipient nephropathy; higher albumin excretion is described as proteinuria. Eventually the condition can lead to renal failure. ${ }^{2}$

Epidemiological studies report prevalence rates of microalbuminuria in patients with type 2 diabetes ranging from $8 \%$ to $32 \%$ with most estimates being around $25 \% .^{4-15}$ Prevalence estimates for proteinuria range from $5 \%$ to $19 \%$ with most studies giving rates of around $15 \% .^{5} 6^{9-11} 1516$ This variation may be a product of the criteria used to define the condition, the stage of the disease, and the methods used to assess it. Figures from the UK Prospective Diabetes Study (UKPDS), based on 3867 patients, suggest that about $12 \%$ have microalbuminuria (although using a high threshold) and $1.9 \%$ have proteinuria at the time of diagnosis of diabetes. ${ }^{17}$ A US study which followed 794 patients with type 2 diabetes who were initially free from proteinuria (defined as $\geqslant 30 \mu \mathrm{g}$ protein/l urine) found that $1.3 \%$ developed renal failure within 10 years. ${ }^{18}$

A substantial proportion of patients treated in renal units in the UK have diabetes. Diabetic nephropathy is the most common single cause of renal failure among adult patients starting renal replacement therapy ( $16 \%$ of the total). ${ }^{19}$ York YO10 5DD, UK $\mathrm{R}$ Richardson, research fellow

D Lister-Sharp, research fellow

ScHARR, University of Sheffield, Sheffield

S1 4DA, UK

A McIntosh, research fellow

Correspondence to: Dr A Melville Arabella_Melville@port 35.freeserve.co.uk

Accepted 18 October 2000 therapy for diabetic renal disease than white Caucasians. ${ }^{31}$ Another survey, which included all 5901 patients accepted for renal replacement therapy by renal units in England, found that people of Asian or Afro-Caribbean origin were almost six times as likely as white Caucasians to receive treatment for diabetic renal failure. $^{32}$ Close relatives of patients with diabetic renal disease are much more likely than others to develop the condition; odds ratios of $3.8(95 \% \text { CI } 1.4 \text { to } 10.4)^{33}$ and 8.1 (95\% CI 2.2 to 29.6$)^{34}$ have been reported.

The majority of studies of blood glucose found associations between higher glycaemia and risk of renal disease. ${ }^{17} 1820212335$

Studies involving $>4000$ participants in total have reported links between raised blood pressure (systolic, diastolic or both) and diabetic renal disease. ${ }^{18} 2126-2835$ Advancing renal disease can lead to increased blood pressure, while increased blood pressure accelerates the course of diabetic renal disease.

Patients with diabetic retinopathy are also more likely to develop renal disease. ${ }^{23} 25$

DISEASE PROGRESSION AND MORTALITY

Longitudinal studies suggest that, while protein excretion tends to increase over time, the rate and direction of change varies between individuals. ${ }^{22}{ }^{36}$ Fewer than $5 \%$ of deaths in patients with type 2 diabetes are directly attributed to renal disease ${ }^{373}$; most result from myocardial infarction, heart failure, or stroke. However, a meta-analysis of eight studies found that the death rate in patients with microalbuminuria was over twice the rate in those with normal urinary albumin (risk ratios 2.4 (95\% CI 1.8 to 3.1$)$ and 2.0 (95\% CI 1.4 to 2.7) for overall and cardiovascular mortality, respectively). ${ }^{39}$ A 12 year study of 4714 patients with diabetes (both types) reported that proteinuria was associated with an eightfold increase in deaths in women and a fivefold increase in men. ${ }^{40}$

IDENTIFYING PATIENTS WITH RENAL DISEASE Urine tests are used to detect and monitor diabetic renal disease. They may measure albumin alone or allow an albumin:creatinine ratio to be calculated. Some are suitable for near patient testing (side room tests) while others require sophisticated laboratory equipment. The former are less accurate but are quicker and easier to use; seven of these are available in the UK.

Evidence was found on the accuracy of the Micral-Test II, Albustix, and Microbumintest. No direct comparisons were identified and there is no evidence that any product is more accurate than others. Sensitivity figures ranged 
from $51 \%^{41}$ to $100 \%^{42-44}$ and specificity from $27 \%{ }^{45}{ }^{46}$ to $97 \%,{ }^{47}$ but different methods, reference standards, ranges, and thresholds were used for these assessments. Any attempt to determine the most effective test is hampered by the heterogeneity of the evidence.

Laboratory tests include radioimmunoassay, immunoturbidimetry, immunonephelometry, enzyme linked immunosorbent assay (ELISA), and the DCA 2000 microalbumin/creatinine assay system. Studies assessing the albumin concentration in urine produced sensitivity and specificity levels above $90 \%$ in only two out of 11 studies, ${ }^{2} 79-54$ one using radioimmunoassay in an early morning sample ${ }^{55}$ and the other using immunonephelometry in a random sample. ${ }^{53}$ Two studies of ELISA in early morning samples $^{749}$ and one using immunoturbidimetry in overnight samples ${ }^{50}$ reported sensitivity of over $80 \%$ and specificity of over $90 \%$. In three studies $^{75152}$ the sensitivity or specificity levels fell below $80 \%$.

All studies of tests measuring albumin:creatinine ratios reported sensitivity and specificity levels above $90 \% .^{74505255-59}$ Accurate measurements were demonstrated with early morning, overnight, and 24 hour samples but the ELISA test on random urine samples achieved only $80 \%$ sensitivity and $81 \%$ specificity. ${ }^{7}$

These tests differ in their nature and have been assessed by methods which may not be directly comparable, so it is not clear which is the most effective or useful. Furthermore, there is very marked day to day variation in urinary albumin excretion and other illness can increase albumin excretion, so a single test on a single day is not reliable. Considered as a whole, the evidence suggests that health professionals should use urine tests on several occasions each year. They should not rely on a single near-patient test to assess diabetic renal disease.

An unpublished British Diabetic Association audit of 47 districts found that $64 \%$ (range 20-96) of patients known to have type 2 diabetes had a renal function test in 1998 .

INTERVENTIONS TO REDUCE RENAL

COMPLICATIONS OF DIABETES

The evidence discussed in this section comes from randomised controlled trials which focus on antihypertensive drugs, blood glucose control, reducing dietary protein, and lipid reducing drugs.

\section{Antihypertensive treatment}

Renal disease was among the outcomes assessed in the UKPDS 38 trial of blood pressure control in patients with type 2 diabetes. ${ }^{60}$ This trial randomised 1148 people to tight or less tight blood pressure control and followed them for a median period of 8.4 years. The mean blood pressure in the two groups was $144 / 82$ and 154/87, respectively. The tight control group had less microvascular disease with a relative risk (RR) for the aggregate end point (which included retinopathy, vitreous haemorrhage, and renal failure) of 0.63 (95\% CI 0.44 to 0.89 ). A trend for reduced renal disease was not statistically significant (RR 0.35, 99\% CI 0.03 to 3.66 and $0.58,99 \%$ CI 0.15 to 2.21 for fatal and non-fatal renal disease, respectively). Five of six surrogate outcomes favoured tight control but only the proportion with microalbuminuria at six years achieved statistical significance $(20.3 \%$ with tight control versus $28.5 \%$ with less tight control; RR = $0.71,99 \%$ CI 0.51 to 0.99$)$.

\section{ACE inhibitors}

Particular attention has focused on angiotensin converting enzyme (ACE) inhibitors which reduce constriction of blood vessels, including those in the kidneys. A large international study $(n=3577)$ comparing an ACE inhibitor (ramipril) with placebo in patients with diabetes (98\% type 2, mean duration 11 years) reported that ramipril reduced both nephropathy and total mortality by $24 \%$ after 4.5 years. ${ }^{61}$ All patients had at least one additional cardiovascular risk factor-hypertension, high cholesterol, microalbuminuria, or smoking.

Many smaller studies have been pooled in a series of meta-analyses. Most of these compare different antihypertensive drugs. A metaanalysis which pooled trials lasting more than a week revealed that ACE inhibitors reduce urinary protein levels significantly more than other antihypertensive drugs in both diabetic and non-diabetic patients. ${ }^{62}$ The mean change in urinary protein with ACE inhibition was $-40 \%(95 \%$ CI -43 to -37$)$ compared with $-17 \%$ (95\% CI -19 to 15 ) for other drugs. Nifedipine (a dihydropyridine calcium channel blocker) had the smallest effect $(-8 \%(95 \% \mathrm{CI}$ -13 to -2$)$ ).

Another review pooled trials with follow up times over six months. ${ }^{63}$ The results again showed that ACE inhibitors reduced urinary protein more than other antihypertensive agents. Analysis of data from 84 trials of mixed designs suggested that the anti-proteinuric effect of ACE inhibitors and nondihydropyridine calcium channel blockers (verapamil, diltiazem) was greater than could be explained by changes in blood pressure. However, this enhanced benefit was not apparent from the meta-analysis of 14 randomised controlled trials only which found that the effects on urinary protein were proportional to changes in blood pressure.

Two other meta-analyses with different inclusion criteria reinforce these results. ${ }^{6465}$ One reported that ACE inhibitors reduced protein excretion by $25 \%$ even when blood pressure remained constant, and that kidney function deteriorated significantly faster in patients with diabetic renal disease treated with nifedipine. ${ }^{65}$

Trials published since these meta-analyses suggest that differences between drugs in their effects on renal function may only be significant in patients who have renal disease. Those with more than 100 patients are discussed below.

The UKPDS 39 study reported no differences between atenolol (a $\beta$ blocker) and captopril (an ACE inhibitor) in 758 patients. ${ }^{66}$ Few of the patients had renal disease and for 
two thirds of the study period $60 \%$ were taking other antihypertensives as well as (or instead of) the drug to which they had been randomised; $35 \%$ of patients on atenolol discontinued treatment because of adverse effects compared with $22 \%$ on captopril $(\mathrm{p}<0.001)$.

A trial in 314 patients with type 2 diabetes, hypertension, and microalbuminuria found that lisinopril (an ACE inhibitor) reduced albumin excretion significantly more than nifedipine. ${ }^{67}$ Similar results were found in a study by De Cesaris et al $l^{68}$ comparing benazapril with nicardipine in 103 patients. Crepaldi et $a l^{69}$ found little difference between lisinopril and nifedipine in 162 patients; although lisinopril seemed to produce greater reduction in albumin excretion in patients with microalbuminuria at baseline (30\%), this was not statistically significant.

A meta-analysis of randomised controlled trials by Lovell $^{70}$ found that ACE inhibitors reduced albumin excretion in patients with diabetes and microalbuminuria, even when their blood pressure was normal. Other randomised controlled trials which were not included in this meta-analysis but which also compared ACE inhibitors (enalapril, ramipril or perindopril) with placebo in patients with mild hypertension or normal blood pressure, diabetes, and microalbuminuria also found that ACE inhibitors reduced albumin excretion. ${ }^{71-73}$ Not only was renal function preserved, but the beneficial effects increased over five years. ${ }^{72} 73$

The evidence therefore demonstrates that ACE inhibitors offer particular benefits for patients with diabetes and renal disease or microalbuminuria, even when normotensive. Dihydropyridine calcium channel blockers such as nifedipine have a less favourable pattern of effects in people with diabetes and renal disease.

Of these trials, only those carried out by the UKPDS assessed renal failure or death rates and none measured quality of life. There seems to be a general and unquestioned assumption that reduction of urinary albumin would inevitably be associated with improvements in such end points. Improvements in surrogate outcome measures such as blood pressure can be associated with deterioration in crucial end points such as life expectancy. ${ }^{74}$ Studies of antihypertensive drug treatment in diabetic renal disease should be designed to detect effects on long term morbidity and mortality.

\section{Improved blood glucose control}

More intensive control of blood glucose may delay the development of renal disease. The UKPDS 33 study $(n=3867)$ reported that the relative risk of microalbuminuria at nine years was 0.76 (99\% CI 0.6 to 0.9$)$ with tight control (mean glycosylated haemoglobin $\left(\mathrm{HbA}_{1 \mathrm{c}}\right)$ $7.0 \%$ ) compared with less tight control (mean $\left.\mathrm{HbA}_{1 \mathrm{c}} 7.9 \%\right) .{ }^{17}$ At 12 years the relative risk fell to $0.67(99 \%$ CI 0.5 to 0.9$)$. It is too soon to know to what degree this may reduce the risk of renal failure.

A Japanese study reported that a mean $\mathrm{HbA}_{1 \mathrm{c}}$ of $7.1 \%$ over a period of six years achieved by relatively frequent use of insulin (multiple injection therapy, MIT) reduced the risk of worsening nephropathy by $70 \%(95 \%$ CI 14 to 89 ) relative to a mean $\mathrm{HbA}_{1 \mathrm{c}}$ of $9.4 \%$ in patients on conventional insulin therapy (CIT). ${ }^{75}$ Of patients with normal renal function at baseline, $7.7 \%$ developed nephropathy in the MIT group and $28 \%$ in the CIT group $(p=0.032)$. Among those with microalbuminuria (defined as urinary albumin excretion $30-300 \mathrm{mg} / 24 \mathrm{~h}$ ), nephropathy progressed in $11.5 \%$ and $32 \%$ of the MIT and CIT groups, respectively $(\mathrm{p}=0.044)$.

\section{Reduced dietary protein}

A systematic review found that a diet containing $0.3-0.8 \mathrm{~g} / \mathrm{kg}$ body weight of protein per day may slow progression to renal failure in subjects with type 1 diabetes. ${ }^{76}$ No reliable evidence was found relating to type 2 diabetes.

\section{Lipid reduction}

No conclusive evidence was found that lipid reduction using statins or gemfibrozil affects renal function. ${ }^{77-80}$ However, these drugs may be appropriate for reduction of cardiovascular morbidity and mortality in patients with diabetes. ${ }^{81}$

\section{MULTIFACTORIAL INTERVENTION}

Four years of intensive multifactorial treatment of patients with microalbuminuria reduced progression of renal disease and improved a range of other diabetes related end points. ${ }^{82}$ The intervention involved tight control of blood pressure, glucose and lipids, ACE inhibitors regardless of blood pressure, advice on diet, vitamin supplements, exercise, and help with smoking cessation. $10 \%$ of patients in the intensively treated group developed nephropathy compared with $24 \%$ in the group which received standard care from GPs (odds ratio $0.27,95 \%$ CI 0.10 to 0.75 ). Blindness and autonomic neuropathy also developed significantly less often in the intensively treated group.

\section{costs}

Tight control of blood pressure is highly cost effective. Analysis of figures derived from the UKPDS 38 study (UKPDS 40), using 1997 values, shows that the incremental cost per life year gained was $£ 720$ with costs and effects discounted at $6 \%$ per year, or $£ 291$ with costs, not effects, discounted. ${ }^{83}$ The analysis was based on unit costs for all NHS resources used by all patients over the entire period of the trial. Tight blood pressure control reduced the rate of complications requiring hospitalisation, which offset the cost of antihypertensive drugs so that net costs for the two groups were not significantly different.

A model suggests that treating all middle aged subjects with diabetes with ACE inhibitors is more cost effective than screening and treating for microalbuminuria or proteinuria, with a cost of $\$ 7500$ for each quality adjusted life year gained. ${ }^{84}$ 
IMPLICATIONS

- The urine of subjects with type 2 diabetes should be tested regularly (at least annually) for proteinuria and, if this is negative, for microalbuminuria. Two or more measurements should be carried out.

- Evidence for the effectiveness of individual near-patient tests used by the NHS is inconclusive.

- The blood pressure of diabetic patients should be checked at regular intervals and treatment offered if it is found to be consistently higher than $140 / 90 .^{85}$

- In those with levels of urinary albumin above normal, treatment with ACE inhibitors is appropriate even if blood pressure is normal.

- Blood glucose levels should be kept as low as is consistent with an acceptable quality of life.

- Further research is required to establish how dietary protein affects progression of renal disease in type 2 diabetes.

\section{Promotion of self-management}

While medical interventions are important in diabetes, long term outcomes depend on choices that patients make themselves. Interventions to help people with type 2 diabetes to change their behaviour fall into to three broad categories: information and skills programmes, cognitive behavioural interventions, and patient empowerment.

These concentrated on everyday diabetes management. Outcome measures included knowledge, skill in diabetes-specific tasks such as glucose testing, adherence to dietary advice, anxiety levels, and rates of hospital admission.

Of 53 relevant randomised clinical trials identified, ${ }^{3}$ seven involved follow up of a year or more and 13 randomised 100 or more participants. Only studies meeting at least one of these criteria were discussed in the bulletin. Reported differences achieved statistical significance at the $\mathrm{p}<0.05$ level. Although five meta-analyses were also identified, their quality was judged to be too poor for the conclusions to be reliable. ${ }^{87-91}$

INFORMATION AND SKILLS PROGRAMMES

Participants in the DIABEDS study $(n=532)$ had lower weight (184 lb (83.6 kg) versus $187 \mathrm{lb}(85 \mathrm{~kg})$ ), blood pressure (diastolic 82 versus $84 \mathrm{~mm} \mathrm{Hg}$, systolic 142 versus $146 \mathrm{~mm} \mathrm{Hg})$ and $\mathrm{HbA}_{1 \mathrm{c}} \quad(-0.43 \%$ versus $+0.53 \%)$ than controls after 11-14 months. $^{92} 93$

In a German study of 1139 patients, intensified health education (individual diet and physical activity advice, physical exercise and anti-smoking groups) had no impact on weight after five years, but participants had lower blood pressure (diastolic 87 versus $92 \mathrm{~mm} \mathrm{Hg}$, systolic 143 versus $154 \mathrm{~mm} \mathrm{Hg}$ ) than controls. $^{94}$

A study that compared home teaching with usual care in 471 subjects found that the intervention led to higher scores for knowledge and skill after six months. ${ }^{95}$ Culture-specific one-toone education for 201 British Asians produced greater improvements than usual care in knowledge, self-care, and attitudes after six months. ${ }^{96}$ After 27 months of a study of six clinic sessions intended to enhance motivation for self-management in 86 subjects, participants used less oral antidiabetic medication than those in the "usual care" group. ${ }^{97}$ Monthly telephone calls from nurses in a one year study in 275 subjects led to lower $\mathrm{HbA}_{1 \mathrm{c}}$ and higher patient satisfaction scores than usual care. ${ }^{98}$

A computer intervention in 105 patients offered personalised dietary information or usual care. ${ }^{99}$ The intervention group had higher knowledge scores than controls but there were no differences in weight or $\mathrm{HbA}_{1 \mathrm{c}}$.

\section{Group interventions}

Participants in a small UK study $(n=75)$ received either group education with specialist nurses or usual care. ${ }^{100}$ After one year the intervention group had higher knowledge scores and had lost more weight than controls $(5.5 \mathrm{~kg}$ versus $3 \mathrm{~kg}$ ) but there were no differences in $\mathrm{HbA}_{1 \mathrm{c}}$ levels.

Another UK study randomised 120 obese participants with limited literacy skills to monthly small group meetings with videos and handouts, similar meetings without videos, or lectures. ${ }^{101}$ Although participants in the video group lost more weight at seven months, this was not sustained. There were no differences in $\mathrm{HbA}_{1 \mathrm{c}}$.

One hundred and seventy hospital inpatients received either a two day "Living with Diabetes" group programme or usual care. ${ }^{102}$ At four months the intervention group reported better compliance with self-care advice than controls.

Participants $(n=120)$ in an Italian study received either four group meetings focusing on diabetes awareness, foot care and changing behaviour, or usual care. ${ }^{103}$ After a year, there were no differences in knowledge, quality of life, weight, or $\mathrm{HbA}_{1 \mathrm{c}}$.

Overall, these studies suggest that individual or group educational interventions can produce small improvements in knowledge, weight, and blood pressure but the clinical significance of these changes is uncertain.

COGNITIVE AND BEHAVIOURAL INTERVENTIONS Cognitive/behavioural interventions are relatively intensive programmes based on the principles of learning theory and/or social cognition models. ${ }^{86}$ In the context of type 2 diabetes, these usually target weight loss through diet and/or exercise. Programmes involve goal setting, problem solving, modification of selfperceptions, the use of behavioural contracts, and sometimes physical exercise.

Two studies of individual programmes involved more than 100 participants. ${ }^{104}{ }^{105}$ In one the 155 participants were randomised to receive usual care or one of three behavioural interventions over one year. ${ }^{105}$ No differences between the groups were found in $\mathrm{HbA}_{1 \mathrm{c}}$ or weight. In an Australian study the 179 participants received individual information sessions, group sessions, or an individual behavioural intervention over one year. ${ }^{104}$ There were no differences in knowledge, satisfaction, $\mathrm{HbA}_{1}$ 
levels, or systolic blood pressure but the behavioural intervention group had a slightly greater fall in diastolic blood pressure at 12 months ( $8 \mathrm{~mm} \mathrm{Hg}$ versus $5 \mathrm{~mm} \mathrm{Hg}$ ).

A study involving 206 participants compared a brief office based computer intervention with usual care. ${ }^{106-108} \mathrm{~A}$ computer assessment was followed by usual care or another assessment and behavioural strategies. After a year there were no differences in weight or $\mathrm{HbA}_{1 \mathrm{c}}$.

In a group intervention study the 76 participants received cognitive/behavioural interventions (diet plus exercise, diet alone, or exercise alone) or information only. ${ }^{109}$ After 18 months there were no differences in weight but the diet plus exercise group had lower $\mathrm{HbA}_{1 \mathrm{c}}$ than controls $(7.7 \%$ versus $8.6 \%)$. In addition, both the combination and diet only groups reported higher quality of life than controls.

In another group study 53 participants were randomised to behaviour modification (16 weekly meetings), nutrition education (16 weekly meetings), or usual care (4 monthly meetings). ${ }^{110}$ There were no differences between groups in weight, physiological measures, eating, or exercise behaviour at 16 months.

Participants $(n=101)$ who received either the "Sixty Something" programme or usual care were assessed immediately after the intervention. ${ }^{111}$ The intervention led to better self-care behaviour and greater weight loss at the end of the programme $(-5.8 \mathrm{lb}(2.6 \mathrm{~kg})$ versus $+1.4 \mathrm{lb}$ $(0.6 \mathrm{~kg}))$ but not at follow up $(-1.9 \mathrm{lb}(0.9 \mathrm{~kg})$ versus $-3.5 \mathrm{lb}(1.6 \mathrm{~kg}))$. There were no differences in $\mathrm{HbA}_{1 \mathrm{c}}$ levels or measures of selfefficacy or mood.

A trial in 55 subjects investigated cognitive/ behaviour therapy to improve diet and encourage exercise. ${ }^{12}$ Participants in the behaviour modification group lost the most weight, but there were no differences in $\mathrm{HbA}_{1 \mathrm{c}}$ levels.

In summary, only one study of a cognitive or behavioural intervention found sustained weight loss, ${ }^{112}$ and one reduced $\mathrm{HbA}_{1 \mathrm{c}}$ levels. ${ }^{109}$ No evidence was found to suggest that either individual or group methods were superior.

PATIENT EMPOWERMENT

These programmes aim to enhance participation in diabetes management, but no reliable evidence was found to support the techniques assessed. ${ }^{113} 114$

\section{IMPLICATIONS}

- Interventions should take into account such factors as age, educational level, and ethnic origin.

- Further research is necessary to determine whether specific interventions to promote self-management have clinically significant long term effects on $\mathrm{HbA}_{1 \mathrm{c}}$ levels, morbidity, quality of life, and mortality.

1 NHS Centre for Reviews and Dissemination. Complications of diabetes: renal disease and promotion of selfmanagement. Effective Health Care 2000;6(1).

2 Hutchinson A, McIntosh A, O'Keeffe C, et al. Type 2 diabetes: systematic review of screening methods and interventions for renal disease. Sheffield: ScHARR, 2000.
3 McIntosh A, Withers H, Hutchinson A. Systematic review on the effectiveness of patient education interventions in on the effectiveness of patient education interventions in
the management of type 2 diabetes. Sheffield: ScHARR, 2000.

4 Allawi J, Rao PV, Gilbert R, et al. Microalbuminuria in noninsulin dependent diabetes: its prevalence in Indian compared with Europid patients. BMF Clin Res Ed 1988;296:462-4

5 Bruno G, Cavallo-Perin P, Bargero G, et al. Prevalence and risk factors for micro- and macroalbuminuria in an Italian population-based cohort of NIDDM subjects. Diabetes Care 1996;19:43-7.

6 Gall MA, Rossing P, Skott P, et al. Prevalence of micro- and macroalbuminuria, arterial hypertension, retinopathy and large vessel disease in European type 2 (non insulin dependent) diabetic patients. Diabetologia 1991;34:655-61.

7 Gatling W, Knight C, Mullee MA, et al. Microalbuminuria in diabetes: a population study of the prevalence and an ssessment of three screening tests. Diabet Med 1988;5: $343-7$.

8 Gupta DK, Verma LK, Khosla PK, et al. The prevalence of microalbuminuria in diabetes: a study from North India. Diabetes Res Clin Pract 1991;12:125-8.

9 Klein R, Klein BEK, Moss SE. Prevalence of microalbuminuria in older-onset diabetes. Diabetes Care 1993;16:1325-

10 Lee KU, Park KY, Kim SW, et al. Prevalence and associated features of albuminuria in Koreans with NIDDM. Diabetes Care 1995;18:793-9.

11 Marshall SM, Alberti KG. Comparison of the prevalence and associated features of abnormal albumin excretion in and associated features of abnormal albumin excretion in insulin-dependent and

12 Mattock M, Morrish NJ, Viberti G, et al. Prospective study of microalbuminuria as predictor of mortality in NIDDM. Diabetes 1992;41:736-41.

13 Mogensen CE. A complete screening of urinary albumin concentration in an unselected diabetic out-patient clinic population. Diabet Nephropathy 1983;2:11-8.

14 Patrick AW, Leslie PJ, Clarke BF, et al. The natural history and associations of microalbuminuria in type 2 diabetes during the first year after diagnosis. Diabet Med 1990;7: 902-8.

15 Standl E, Stiegler H. Microalbuminuria in a random cohort of recently diagnosed type 2 (non-insulin dependent) diabetic patients living in the greater Munich area. Diabetologia 1993;36:1017-20.

16 Vijay V, Snehalatha C, Ramachandran A, et al. Prevalence of proteinuria in non-insulin dependent diabetes. F Assoc Physicians India 1994;42:792-4.

17 UK Prospective Diabetes Study (UKPDS) Group. Intensive blood-glucose control with sulphonylureas or insulin compared with conventional treatment and risk of complications in patients with type 2 diabetes (UKPDS 33). Lancet 1998;352:837-53.

18 Klein R, Klein BEK, Moss SE, et al. Ten-year incidence of gross proteinuria in people with diabetes. Diabetes 1995;44: $916-23$

19 Ansell D, Feest T, Will E, et al. The second annual report of the UK Renal Registry. Bristol: The UK Renal Registry, 1999.

20 Mattock MB, Barnes DJ, Viberti G, et al. Microalbuminuria and coronary heart disease in NIDDM: an incidence study. Diabetes 1998;47:1786-92.

21 Niskanen LK, Penttila I, Parviainen M, et al. Evolution, risk factors, and prognostic implications of albuminuria in NIDDM. Diabetes Care 1996;19:486-93.

22 Wirta OR, Pasternack AI, Mustonen JT, et al. Urinary albumin excretion rate and its determinants after 6 years in non-insulin-dependent diabetic patients. Nephrol Dialysis Transplant 1996;11:449-56.

23 Gall M, Hougaard P, Borch-Johnsen K, et al. Risk factors for development of incipient and overt diabetic nephropathy in patients with non-insulin dependent diabetes mellitus: prospective, observational study. BMF 1997;314:783-8.

24 Biesenbach G, Grafinger P, Janko O, et al. Influence of cigarette-smoking on the progression of clinical diabetic nephropathy in type 2 diabetic patients. Clin Nephrol 1997; 48:146-50.

25 Sasaki A, Horiuchi N, Hasagawa K, et al. Persistent albuminuria as an index of diabetic nephropathy in type 2 diabetic patients in Osaka, Japan: incidence, risk factors, prognosis and causes of death. Diabetes Res Clin Pract 1989;7:299-306.

26 Nielsen S, Schmitz A, Poulsen PL, et al. Albuminuria and 24-h ambulatory blood pressure in normoalbuminuric and microalbuminuric NIDDM patients. A longitudinal study. Diabetes Care 1995; 18:1434 pat.

27 Ravid M, Brosh D, Ravid Safran D, et al. Main risk factors for nephropathy in type 2 diabetes mellitus are plasma for nephropathy in type 2 diabetes mellitus are plasma
cholesterol levels, mean blood pressure, and hyperglycemia. Arch Intern Med 1998;158:998-1004.

28 Schmitz A, Vaeth M, Mogensen CE. Systolic blood pressure relates to the rate of progression of albuminuria in NIDDM. Diabetologia 1994;37:1251-8.

29 Davis TM, Stratton IM, Fox CJ, et al. UK Prospective Diabetes Study 22. Effect of age a diagnosis on diabetic tissue damage during the first 6 years of NIDDM. Diabetes Care 1997;20:1435-41.

30 John L, Rao PS, Kanagasabapathy AS. Rate of progression of albuminuria in type II diabetes, five year prospective study from South India. Diabetes Care 1994;17:888-90.

31 Burden AC, McNally PG, Feehally J, et al. Increased incidence of end stage renal failure secondary to diabetes 
mellitus in Asian ethnic groups in the United Kingdom. Diabet Med 1992;9:641-5.

32 Roderick PJ, Raleigh VS, Hallam L, et al. The need and demand for renal replacement therapy in ethnic minorities in England. F Epidemiol Community Health 1996;50:334-9.

33 Canani LH, Gerchman F, Gross JL. Familial clustering of diabetic nephropathy in Brazilian type 2 diabetic patients. Diabetes 1999;48:908-13.

34 Freedman BI, Tuttle AB, Spray BJ. Familial predisposition to nephropathy in African-Americans with non-insulindependent diabetes mellitus. Am $\mathcal{F}$ Kidney Dis 1995;25: $710-3$.

35 Tanaka Y, Atsumi Y, Matsuoka K, et al. Role of glycemic control and blood pressure in the development and progression of nephropathy in elderly Japanese NIDDM patients. Diabetes Care 1998;21:116-20.

36 Niskanen L, Voutilainen R, Terasvirta M, et al. A prospective study of clinical and metabolic associates of prospective study of clinical and metabolic associates of proteinuria in patient

37 Gall MA, Borch-Johnsen K, Hougaard P, et al. Albuminuria and poor glycemic control predict mortality in NIDDM Diabetes $1995 ; 44: 1303-9$.

38 Schmitz A, Vaeth M. Microalbuminuria: a major risk factor in non-insulin-dependent diabetes. A 10-year follow-up study of 503 patients. Diabet Med 1988;5:126-34.

39 Dinneen SF, Gerstein HC. The association of microalbuminuria and mortality in non-insulin-dependent diabetes mellitus: a systematic overview of the literature. Arch Intern Med 1997;157:1413-8.

40 Wang SL, Head J, Stevens L, et al. Excess mortality and its relation to hypertension and proteinuria in diabetic patients: the World Health Organisation Multinational Study of Vascular Disease in Diabetes. Diabetes Care 1996; 19:305-12.

41 Bashyam MM, O'Sullivan NJ, Baker HH, et al. Microalbuminuria in NIDDM. Diabetes Care 1993;16:634-5.

42 Williams BT, Ketchum CH, Robinson CA, et al. Screening for slight albuminuria: a comparison of selected commercially available methods. South Med $\mathcal{F}$ 1990;83:1447-9.

43 Tiu SC, Lee SS, Cheng MW. Comparison of six commercial techniques in the measurement of microalbuminuria in diabetic patients. Diabetes Care 1993;16:616-20.

44 Giampietro O, Penno G, Clerico A, et al. Which method for quantifying "microalbuminuria" in diabetics? Comparison of several immunological methods (immunoturbidimeteric assay, immunonephelometric assay, radioimmunoassay and two semi quantitative tests) for measurement of albumin in two semi quantitative tests) for meas

45 Leedman PJ, Nankervis A, Goodwin M, et al. Assessment of the Albuscreen microalbuminuria kit in diabetic outpathe Albuscreen microalbuminuria
tients. Med $\mathcal{F}$ Aust 1987;147:285-6.

46 Colwell M, Halsey JF. High incidence of false-positive albuminuria results with the Micro-Bumintest. Clin Chem minuria results

47 Al-Kassab AS. Evaluation of a simple method for the screening of microalbuminuria in diabetic patients. Scand $\mathcal{F}$ Clin Lab Invest 1990;50:913-5.

48 Collins V, Zimmet P, Dowse GK, et al. Performance of "Micro-Bumintest" tablets for detection of microalbuminuria in Nauruans (West Pacific Ocean). Diabetes Res Clin Pract 1989;6:271-7.

49 Gatling W, Knight C, Hill RD. Screening for early diabetic nephropathy: which sample to detect microalbuminuria? Diabet Med 1985;2:451-5.

50 Bakker AJ. Detection of microalbuminuria. Receiver operating characteristic curve analysis favors albumin-tocreatinine ratio over albumin concentration. Diabetes Care 1999;22:307-13.

51 Kouri TT, Viikari JSA, Mattila KS, et al. Microalbuminuria: invalidity of simple concentration-based screening tests for early nephropathy due to urinary volumes of diabetic patients. Diabetes Care 1991:14:591-3.

52 Marbut K, Lane J. A new sensitive ELISA test for spot test of urinary albumin. Clin Chem 1992;36:1430-1.

53 Sawicki PT, Heinemann L, Berger M. Comparison of methods for determination of microalbuminuria in diabetic patients. Diabet Med 1989;6:412-5.

54 Bouhanick B, Berrut G, Chameau AM, et al. Predictive value of testing random urine sample to detect microalbuminuria in diabetic subjects during outpatient visit. Diabete et Metabolisme 1992;18:54-8.

55 Hutchison AS, O'Reilly DS, MacCuish AC. Albumin excretion rate, albumin concentration, and albumin/creatinine tion rate, albumin concentration, and albumin/creatinine
ratio compared for screening diabetics for slight albuminratio compared for screening diab
uria. Clin Chem 1988;34:2019-21.

56 Nathan DM, Rosenbaum C, Protasowicki VD. Single-void urine samples can be used to estimate quantitative
microalbuminuria. Diabetes Care 1987;10:414-8.

57 Connell SJ, Hollis S, Tieszen KL, et al. Gender and the clinical usefulness of the albumin:creatinine ratio. Diabe Med 1994;11:32-6.

58 Parsons M, Newman DJ, Pugia M, et al. Performance of a reagent strip device for quantitation of the urine albumin: creatinine ratio in a point of care setting. Clin Nephrol 1999;51:220-7.

59 Poulsen PL, Mogensen CE. Clinical evaluation of a test for immediate and quantitative determination of urinary albumin-to-creatinine ratio. A brief report. Diabetes Care 1998;21:97-8.

60 UK Prospective Diabetes Study Group. Tight blood pressure control and risk of macrovascular and microvascular complications in type 2 diabetes: UKPDS $38 . B M Y$ 1998;317:703-13.
61 Heart Outcomes Prevention Evaluation (HOPE) Study Investigators. Effects of ramipril on cardiovascular and microvascular outcomes in people with diabetes mellitus: results of the HOPE study and MICRO-HOPE substudy. Lancet 2000;355:253-9.

62 Gansevoort RT, Sluiter WJ, Hemmelder MH, et al. Antiproteinuric effect of blood-pressure-lowering agents: a metaanalysis of comparative trials. Nephrol Dialysis Transplant 1995;10:1963-74.

63 Maki DD, Ma JZ, Louis TA, et al. Long-term effects of antihypertensive agents on proteinuria and renal function. Arch Intern Med 1995;155:1073-80.

64 Kasiske BL, Kalil RS, Ma JZ, et al. Effect of antihypertensive herapy on the kidney in patients with diabetes: a meta-regression analysis. Ann Intern Med 1993;118:129 38

65 Weidmann P, Schneider M, Bohlen L. Therapeutic efficacy of different antihypertensive drugs in human diabetic nephropathy: an updated meta-analysis. Nephrol Dialysis Transplant 1995;10:39-45.

66 UK Prospective Diabetes Study Group. Efficacy of atenolol and captopril in reducing risk of macrovascular and microvascular complications in type 2 diabetes: UKPDS 39. BMF 1998;317:713-20.

67 Agardh CD, Garcia Puig J, Charbonnel B, et al. Greater reduction of urinary albumin excretion in hypertensive type II diabetic patients with incipient nephropathy by lisinopril than by nifedipine. F Human Hypertens 1996;10: $185-92$

68 De Cesaris R, Ranieri G, Andriani A, et al. Effects of benazepril and nicardipine on microalbuminuria in normotensive and hypertensive patients with diabetes. Clin Pharmacol Therap 1996;60:472-8.

69 Crepaldi G, Carraro A, Brocco E, et al. Hypertension and non-insulin dependent diabetes. Acta Diabetol 1995;32: 203-8.

70 Lovell HG. Are angiotensin converting enzyme inhibitors useful for normotensive diabetic patients with microalbuminuria? (Cochrane Review). The Cochrane Library. Oxford: Update Software, 1999.

71 Trevisan R, Tiengo A. Effect of low-dose ramipril on microalbuminuria in normotensive or mild hypertensive noninsulin-dependent diabetic patients. North-East Italy Microalbuminuria Study Group. Am F Hypertens 1995;8: 876-83.

72 Ahmad J, Siddiqui MA, Ahmad H. Effective postponement of diabetic nephropathy with enalapril in normotensive type 2 diabetic patients with microalbuminuria. Diabetes Care 1997;20:1576-81.

73 Ravid M, Brosh D, Levi Z, et al. Use of enalapril to attenuate decline in renal function in normotensive, normoalbuminuric patients with type 2 diabetes mellitus: a randomized, controlled trial. Ann Intern Med 1998;128:982-8.

74 Gøtzsche PC, Liberati A, Torri V. Beware of surrogate outcome measures. Int $\mathcal{F}$ Technol Assessment Health Care 1996; 12:238-46.

75 Ohkubo Y, Kishikawa H, Araki E, et al. Intensive insulin therapy prevents the progression of diabetic microvascular complications in Japanese patients with non-insulindependent diabetes mellitus: a randomized prospective 6-year study. Diabetes Res Clin Pract 1995;28:103-17.

76 Waugh NR, Robertson AM. Protein restriction in diabetic renal disease (Cochrane Review). In: The Cochrane Library. Oxford: Update Software, 1999

77 Tonolo G, Ciccarese M, Brizzi P, et al. Reduction of albumin excretion rate in normotensive microalbuminuric type 2 diabetic patients during long-term simvastatin treatment. Diabetes Care 1997;20:1891-5.

78 Smulders YM, Van Eeden AE, Stehouwer CDA, et al. Can reduction in hypertriglyceridaemia slow progression of microalbuminuria in patients with non-insulin dependent diabetes mellitus? Eur f Clin Invest 1997;27:997-1002.

79 Nielsen S, Schmitz O, Moller N, et al. Renal function and insulin sensitivity during simvastatin treatment in type 2 (non-insulin-dependent) diabetic patients with microalbuminuria. Diabetologia 1993;36:1079-86.

80 Lam KSL, Cheng IKP, Janus ED, et al. Cholesterol-lowering therapy may retard the progression of diabetic nephropathy. Diabetologia 1995;38:604-9.

81 NHS Centre for Reviews and Dissemination. Cholesterol and coronary heart disease: screening and treatment. Effective Health Care 1998;4:1-16.

82 Gaede P, Vedel P, Parving HH, et al. Intensified multifactorial intervention in patients with type 2 diabetes mellitus and microalbuminuria: the Steno type 2 randomised study. Lancet 1999;353:617-22.

83 UK Prospective Diabetes Study Group. Cost effectiveness analysis of improved blood pressure control in hypertensive patients with type 2 diabetes: UKPDS 40. BMF 1998;317: $720-6$

84 Golan L, Birkmeyer JD, Welch G. The cost-effectiveness of treating all patients with type 2 diabetes with angiotensin converting enzyme inhibitors. Ann Intern Med 1999;131: $660-7$.

85 Ramsay LE, Williams B, Johnston GD, et al. British Hypertension Society guide

86 Bandura A. Social learning theory. New Jersey: Prentice-Hall, 1977.

87 Brown SA. Effects of educational interventions in diabetes care: a meta-analysis of findings. Nursing Res 1988;37:22330 . 
88 Brown SA. Studies of educational interventions and outcomes in diabetic adults: a meta-analysis revisited. outcomes in diabetic adults: a meta-an
Patient Educ Counselling 1990;16:189-215.

89 Brown SA. Meta-analysis of diabetes patient education research: variations in intervention effects across studies. Res Nurs Health 1992;15:409-19.

90 Brown SA, Upchurch S, Anding R, et al. Promoting weight loss in type II diabetes. Diabetes Care 1996;19:613-24.

91 Padgett D, Mumford E, Hynes M, et al. Meta-analysis of the effects of educational and psychosocial interventions on management of diabetes mellitus. F Clin Epidemiol 1988;41: $1007-30$

92 Mazzucca S, Moorman N, Wheelder M, et al. The Diabetes Education Study: a controlled trial of the effects of diabetes patient education. Diabetes Care 1986:9:1-10.

93 Vinicor F, Cohen SJ, Mazzuca SA, et al. DIABEDS: a randomized controlled trial of the effects of physician and/or patient education on diabetes patient outcomes. F Chronic Dis 1987;40:345-56.

94 Hanefeld M, Fischer S, Schmechel H, et al. Diabetes intervention study: multi-intervention trial in newly diagnosed vention study: multi-intervention trial in
NIDDM. Diabetes Care 1991;14:308-17.

95 Rettig BA, Shrauger DG, Recker RR, et al. A randomised study of the effects of a home diabetes education program. Diabetes Care 1986;9:173-8.

96 Hawthorne K, Tomlinson S. One to one teaching with pictures: flashcard health education for British Asians with diabetes. Br f Gen Pract 1997;47:301-4.

97 Uusitupa M, Laitinen J, Siitonen O, et al. The maintenance of improved metabolic control after intensified diet therapy in recent type 2 diabetes, Diabetes Res Clm Pract 1993;19:227-38

98 Kirkman SM, Weinberger M, Landsman PB, et al. A telephone-delivered intervention for patients with NIDDM. Effect on coronary risk factors. Diabetes Care 1994;17:840-6.

99 Turnin MG, Beddok RH, Clottes JP, et al. Telematic Expert System Diabeto. New tool for diet self-monitoring for diabystem Diabeto. New tool for diet self-monitoring for dia-

00 .

0 Heller SR, Clarke P, Daly H, et al. Group education for obese patients with type 2 diabetes: greater success at less cost. Diabet Med 1988;5:552-6.

101 Mulrow C, Bailey S, Sonksen PH, et al. Evaluation of an audiovisual diabetes education program: negative results of a randomised trial of patients with non-insulin dependen diabetes. F Gen Intern Med 1987;2:215-9.
102 Wood ER. Evaluation of a hospital-based education program for patients with diabetes. I Am Dietetic Assoc 1989;89:354-8.

103 Trento M, Passera P, Tomalino M, et al. Therapeutic group education in the follow-up of patients with non-insulin reated, non-insulin dependent diabetes mellitus. Diabetes Nutr Metab Clin Exp 1998;11:212-6.

104 Campbell EM, Redman S, Moffitt PS, et al. The relative effectiveness of educational and behavioral instruction programs for patients with NIDDM: a randomised trial. Diabetes Educator 1996;22:379-86.

105 Boehm S, Schlenk EA, Raleigh E, et al. Behavioral analysis and behavioral strategies to improve self-management of and behavioral strategies to improve self-manag
type II diabetes. Clin Nurs Res 1993;2:327-44.

106 Glasgow RE, Toobert DJ, Hampson SE. A brief officebased intervention to facilitate diabetes dietary selfmanagement. Health Educ Res 1995;10:467-78.

107 Glasgow RE, Toobert DJ, Hampson SE. Effects of a brief office-based intervention to facilitate diabetes dietary self-management. Diabetes Care 1996;19:835-42.

108 Glasgow RE, La Chance PA, Toobert DJ, et al. Long term effects and costs of brief behavioural dietary intervention for patients with diabetes delivered from the medical office. Patient Educ Counselling 1997;32:175-84.

109 Hartwell S, Kaplan R, Wallace J. Comparison of behavioral interventions for control of type II diabetes. Behav Therapy 1986;17:447-61.

110 Wing RR, Epstein LH, Nowalk MP, et al. Behavior change, weight loss, and physiological improvements in type II diabetic patients. F Consulting Clin Psychol 1985;53:111-22.

111 Glasgow RE, Toobert DJ, Hampson SE, et al. Improving self-care among older patients with type II diabetes: The "Sixty Something ..." study. Patient Educ Counselling 1992; 19:61-74.

112 Heitzmann CA, Kaplan RM, Wilson DK, et al. Sex differences in weight loss among adults with type ii diabetes mellitus. F Behav Med 1987;10:197-211.

113 Falkenberg MGK, Elwing BE, Goransson AM, et al. Problem oriented participatory education in the guidance of lem oriented participatory education in the guidance of Scand F Primary Health Care 1986;4:157-64.

114 Noel PH, Larme AC, Meyer J, et al. Patient choice in diabetes education curriculum. Nutritional versus standard content for type 2 diabetes. Diabetes Care 1998;21:896901. 